\title{
Text and Image: Books and Film in Dialogue
}

by Kevin Waldie

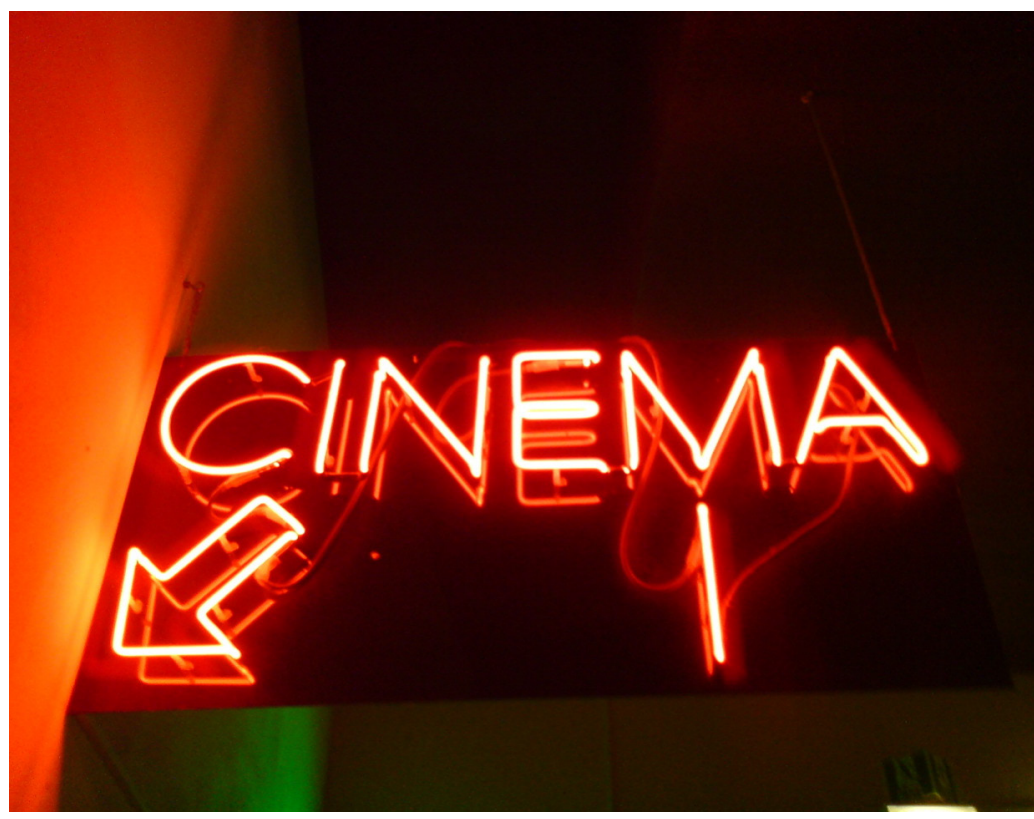

Y ou and I are people of the written text. It is our job to oversee and tend to that text in its various forms. Also in contention in our work is a recognition of the relationship between the sacred and the profane. In many ways those two spheres are not that far apart from each other. And that is crucial to my work as a scholar and a human being. Because my primary task is concerned with gaining deeper insights into the biblical text, using all the academic means available to me and encouraging others to join me in unravelling the mysteries of that sacred text, I am constantly looking beyond that narrow domain to engage with a broader forum of world-views and opinions.

Working full time with a written source, the printed Word of God, I am always reminded that it comes to me in a form that both reveals and conceals its content and the history of its transmission, in addition to the nature of its specific literary content. Therefore delving into that book of books requires of me and you not only the need for certain knowledge and skills to apply that knowledge in a disciplined manner but also an ability to employ the powers of imagination as a perhaps too long neglected tool in the reception of the text.

In a sense then we have to take seriously how the biblical text reflects or mirrors the real world. I would dare to say that most people have never been conscious of this. The more I become conversant with the stories and traditions of the many and varied books which make up our Old and New Testaments the more I realise just how wonderfully down-to-earth and all-embracing the biblical narrative is when it reads as revelation.

To be able therefore to call upon one's imagination and use it critically in the reading of a text, be it biblical or secular, in my opinion is a vital ingredient in the search for self-understanding 


\section{"To be able therefore to call upon one's imagination and use it critically in the reading of a text... is a vital ingredient in the search for self-understanding"}

and the meaning of life. Having spent many hours in cinemas over the years I have come to a similar judgment with respect to the celluloid image that is projected on the silver screen before me. Of course, not all films succeed in their purpose or demonstrate that the director and scriptwriter have exercised sufficient skill in telling their story. However, there is many a film that strikes the right note, where narrative and image combine in such a way as to elicit from us varying responses which ultimately relate to (1) life's highs and lows within familial and societal contexts, (2) forces for good and bad, and (3) a myriad of human situations in which ordinary people find themselves.

So for me, and probably for you too, there is something parabolic in the way written texts, notably fiction, and cinematic texts function. Since my standard reference point is the Bible I cannot help then but see its influence and themes everywhere, both in the world's secular literature and in the vast library or archive of moving pictures that have made it onto the world's cinema screens.

Today, I have chosen a few examples from recent films that may illustrate the importance of the relationship between text and image and then the dialogue that is possible between an author's written text and the interpretation it may be given through the medium of film.

Obviously, there is not always agreement on how well a source text has been transferred to the silver screen. If we have read a certain written text before seeing a particular film we will have no doubt already assembled some fixed images and associations in our mind and imagination. As a consequence we will expect to see our perception of the text presented on film; and if those expectations are not met we will necessarily feel disappointed. That is why I personally prefer to work the other way around: after I have seen a film I like to go back to the written text that inspired someone to give it a new form. Clearly, a different dynamic is at work when it is transformed in this way. But let me say forthwith that I do not always work by that principle, especially when I am watching films in quasi parallel with the biblical text, that is where the ancient literature of Sacred Scripture in its own way may have already dealt with the themes and plotlines shown and told to me in the cineplex.

So to the precise matter that I want to present to you today. If you look closely enough at the credits which begin or conclude a film you will more than likely notice that there is frequently an acknowledgement that this story is based on or inspired by a novel, a short story, someone's memoirs, a true story etc. That is a signal for us to regard the film's content and form with either a sort of reverence for or cynicism towards what the medium of film may do in the manner it adopts to tell the story. For a film is not the book and nor is a book the film. By necessity each medium of communication relies upon a set of genre-specific stimuli that engage the viewer or the reader. Being a slave to the written text 


\section{Children's Literature}

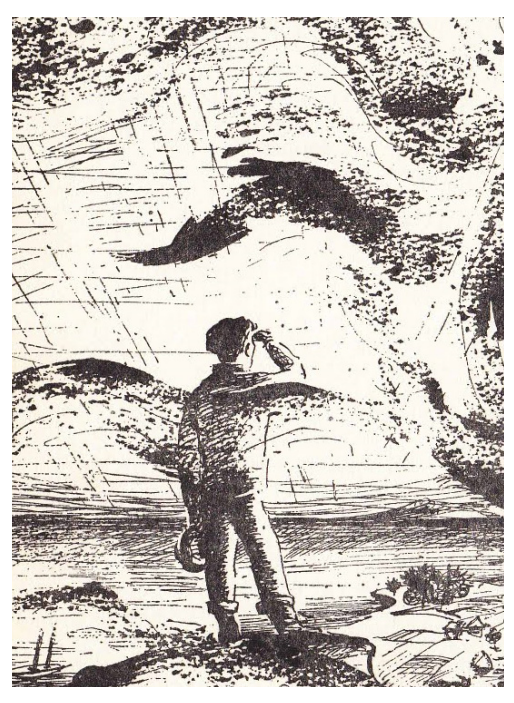

\section{Everyday Relationships}

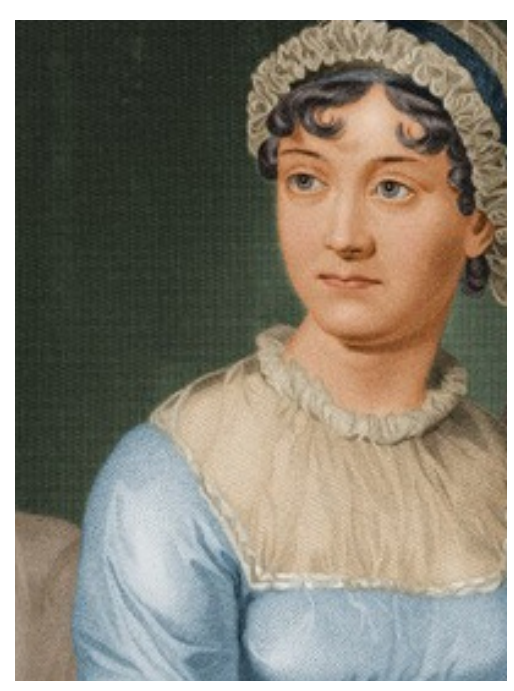

in the production of a film more often than not means that the film loses touch with its own identity as a genre of expression and therefore fails to utilise its potential to convey elements of the story via a means outside the bounds of the written word as a medium of communication.

Without fail, in every year of new film releases there are some striking examples of written texts transformed into cinematic versions of themselves. Some usually come from (1) the domain of children's literature, some from (2) the everyday world of adult human relationships, and others from (3) the dark side of life where sin and violence hold sway.

So the clips that I have selected today are seen as representative of a particular author's intent and narrative style and the interpretation provided through the lens and creative art of the director and scriptwriter.

I think we can all agree that children's fantasy worlds supply plenty for both adult and child to enjoy; frequently, they also offer us issues to debate which take the story to a new level, often contending with things philosophical and religious. "The Golden Compass" by Philip Pullman is one such example. Alongside of it we might place another one to rival it which has only very recently appeared, that is "The Chronicles of Narnia: Prince Caspian" by C.S. Lewis. Both stories come at their subject matter from different poles of the religious spectrum, the former utterly anti-Christian, the latter profoundly Christian. Not quite in the same league as these two is another children's film, interesting in its own right because of its source material, that is "The Spiderwick Chronicles" by Holly Black and illustrated by Tony DiTerlizzi. Dealing with all the familiar themes it uniquely presents a multi-volume story in just one film thus avoiding the usual expectation of sequels. In each of these a world of literary history forms the backdrop and over-arching premise for what we see presented on the silver screen.

On a different level there is the world that is represented by "The Jane Austen Book Club" written by Karen Joy Fowler and "Becoming Jane" by Jon Spence. Both these movies are imaginative recreations of the personality and writings of the author Jane Austen. In each instance we are confronted with the reality of love experienced in its various shapes and forms. Seeking for love and how that love either manifests itself or is stifled is the matter for reflection here. No one can escape this desire but just how we handle it and conceive of it is the challenge that is in store for every reader and viewer. In something of a similar vein I would also include "The Painted Veil" by Somerset Maughan. This story takes place in 1927, in China, and tells the story of a doctor and his wife who struggle to live a loving, happy and honest life together. What happens during their stint in the disease-ridden back blocks of China alters their lives and their love for each other. 


\section{The Dark Side}

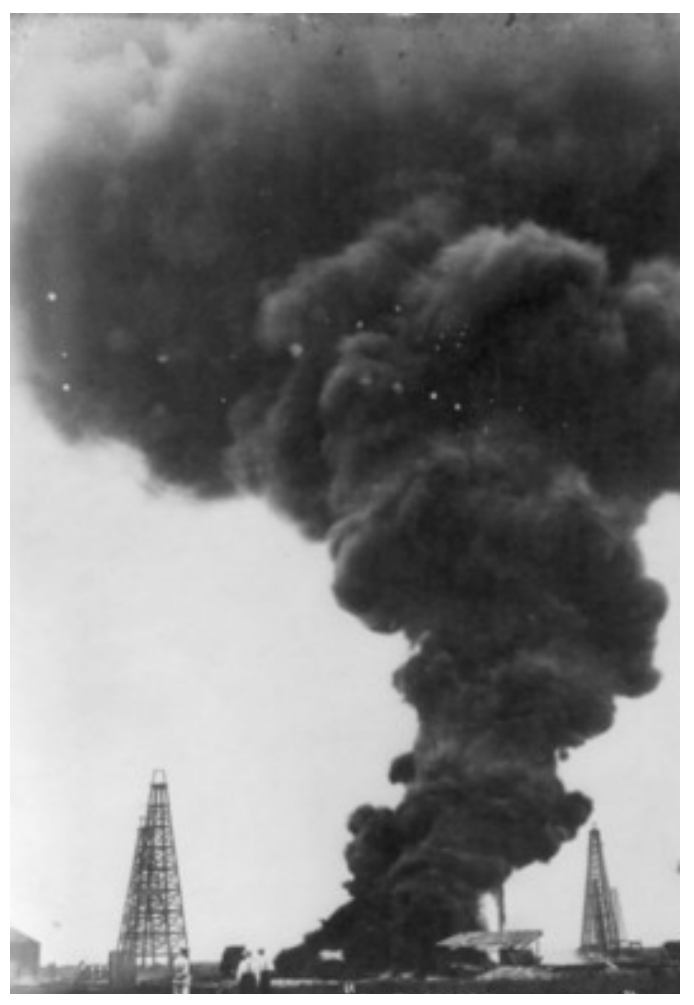

In the realm of darkness, greed and deception a recent film to catch my eye and imagination is the story "There will be Blood" penned by Upton Sinclair under the title "Oil". It offers an insight into the role money and religion can play in life. What we see and hear at first does not necessarily tell us the truth about its characters, their relationships and their dealings with one another. We only gradually learn the story's secrets and the destiny that is thus dictated for its characters. Throughout the film the dynamic of the visual is to the fore; the first ten minutes demonstrate this well in that we sit there watching what happens rather unusually without any dialogue whatsoever; in this way we are introduced to the main character and the story's subject matter, relying upon a sequence of purely visual storytelling. From that point on we are drawn into a story that is brutal and disconcerting in its tenor but without us quite knowing what the final outcome will be. It is a tale of humankind very much in need of redemption and not necessarily finding it. Slightly different yet related is "Gone, Baby, Gone" by Dennis Lehane. This story is set in Boston and tells the tale of a young girl seemingly abducted and murdered. What the truth is though only comes to light after we have watched the characters and the images of their disturbed lives unfold. We become immersed in the mystery and it is not beautiful but it is real.

Our brief foray into the world of text and image demonstrates for me how texts, both written and cinematic, have a common and indispensable role to play in our world. And of course that text which is the Bible holds a key place in my religious and literary worlds; as an ancient revered and inspired collection it reminds me that whatever I read in modern literature or see up on the silver screen is not without equal in the stories, themes and characters found on the pages of Scripture. Being able to appreciate this grand literary history and the newer interpretations of life and the human condition is a blessing and a joy that I hope you too can readily relate to. If 